\title{
Do interesse nacional à estratégia de segurança energética: um diálogo epistemológico
}

\section{From the national interest to energy security strategy: an epistemological dialogue}

\section{INTRODUÇÃO}

Desde o primeiro grande choque do petróleo, em 1973, a seara energética global tem apresentado uma série de acontecimentos que colocam em xeque a supremacia dos hidrocarbonetos. Um dos pontos de inflexão recentes mais significativos desse movimento é a exploração e produção do xisto, tornando-se competitivo em decorrência do avanço tecnológico e da estabilização do preço do petróleo entre 2009 e 2013, apesar do grande declínio do preço a partir de 2014. Um segundo movimento, o da expansão lenta das energias renováveis, também sugere um redesenho na geopolítica energética global. Entretanto, incertezas concernentes à configuração geopolítica energética global emergem.

De acordo com Blackwill e O’Sullivan (2014), o mapa energético global está sendo redesenhado: o petróleo africano, por exemplo, é direcionado para a Ásia, em vez de endereçado aos EUA, apresentando mudanças de rotas deste recurso. Manning (2014) sugere que o novo centro de gravidade energético mundial penderá para o hemisfério Ocidental (Canadá, EUA, México e Brasil), onde grandes e promissoras reservas de xisto estão localizadas. Essa nova dinâmica abre espaço para que a China intensifique sua presença no Oriente Médio, deflagrando uma nova "rota da seda” por petróleo (Manning 2014). Por conseguinte, a produção global de combustíveis fósseis desloca-se dos fornecedores tradicionais da Eurásia e do Oriente Médio para outras regiões, como o Mediterrâneo e o continente americano, confluindo em novas dinâmicas energéticas.

Tiago Gabriel Tasca - Mestre em Política Internacional e Comparada na Universidade de Brasília. 
Outrossim, novas rotas energéticas serão intensificadas e outras enfraquecidas com a expansão da produção de gás natural liquefeito (GNL), que impacta diretamente a indústria petrolífera global. Exemplo disso é a intensificação de uma rota geoenergética entre EUA e o continente asiático para exportar GNL. Segundo dados da Bristish Petroleum (BP 2017), esse continente apresentará as maiores demandas por GNL até 2035, e os EUA apresentar-se-ão como mercado de maior expansão de produção de GNL entre 2020 e 2035. Além disso, a expansão do xisto na Eurásia também tem impactos significativos na redução da dependência da Ucrânia do gás natural e petróleo russos que este país importa e que já foi alvo de crises recentes, com a interrupção do fornecimento russo de gás para a Ucrânia, em retaliação à crise política que se desenhou em torno da Crimeia. Tendo em vista esse cenário incerto, um melhor enquadramento analítico apresenta-se como ferramenta valiosa para os estudiosos da área.

À luz desses desafios, é necessário reconhecer que o desenvolvimento da sociedade moderna se confunde com o desenvolvimento das fontes energéticas e, junto a ele, as questões abarcadas pela economia política da energia envolvem temas securitários, políticos, econômicos e geoestratégicos. Nesse sentido, a busca por estratégias de suprimento seguro a preços razoáveis apresenta-se como um dos motes da busca da segurança energética.

Contudo, compreender o que os Estados consideram vital à sua segurança energética têm priorizado questões geopolíticas de acesso e diversificação das fontes energéticas para dar sustentação ao desenvolvimento econômico das nações. É aqui que se insere esse estudo, visando a estreitar os laços entre os estudos de Teorias de Relações Internacionais, sobretudo Realismo, Neorrealismo e Construtivismo, à luz de uma abordagem geopolítica para o tema da energia em sentido amplo enquanto conceito passível da agenda estratégica dos Estados.

Nesse esforço, busca-se conjugar aspectos que vão desde o interesse nacional, sua construção e consecução até a estratégia de segurança energética sustentada pela diversificação de fontes e de parceiros. Para levar a cabo esse objetivo, uma revisão da literatura foi feita a fim de estabelecer um diálogo epistemológico de como os assuntos de geopolítica energética são inseridos na agenda de RI, utilizando premissas de estudos de segurança internacional (Buzan e Hansen 2009, Klare 2006, Yergin 2011), geopolítica (Couto e Silva 1980, Mattos 2011) e economia política (Krasner 1978, Fuser 2013, Hage 2008, Graaf et al. 2016). Essa inserção se dá por meio de seu componente estratégico, considerando o mundo caracterizado pela alta dependência de fontes não-renováveis (petróleo, sobretudo) e por uma lenta penetração de combustíveis limpos. 
Essa narrativa divide-se em duas partes. Primeiro, são estabelecidas algumas direções teóricas no seio das Teorias de Relações Internacionais e o componente do interesse nacional, ilustrando uma conexão entre abordagens positivistas com abordagem pós-positivista. A partir dessas direções, faz-se o esforço de conjugar esses elementos com a Geopolítica, enfatizando a abordagem brasileira de Objetivos Nacionais Permanentes e Atuais (Couto e Silva 1980). Em um segundo momento, apresentam-se os elos da Geopolítica e das TRI com os Estudos de Segurança Internacional, a fim de evidenciar de que forma se configuram as Estratégias de Segurança Energética, sem perder de vista a pedra de toque da narrativa: a Geopolítica Energética.

\section{O INTERESSE NACIONAL: DA CONSTRUÇÃO À CONSECUÇÃO}

O poder, dentro das Relações Internacionais, desempenha um papel central na moldagem das relações entre os Estados. Nesse sentido, o trabalho de Hans Morgenthau, em Política Entre as Nações (2003), lança as primeiras linhas sobre uma teoria Realista da política internacional. Uma vez reconhecida, pela ótica Realista, a política internacional como a luta pelo poder, Morgenthau articula os conceitos de interesse e poder: aquele em função deste, englobando laços psicológicos e relacionamentos sociais. Por essa abordagem, o interesse que vai determinar a ação política varia em um determinado período da história e também é dependente "do contexto político e cultural dentro do qual é formulada a política externa" (Morgenthau 2003, 18).

Morgenthau (2003), dando sustentação às premissas do Realismo político, também articula que os Estados perseguem o interesse nacional por políticas voltadas para a busca do poder e da sua sobrevivência. Nesse contexto, ele separa as high politics (questões estratégico-militares) das low politics (decisões econômicas), enquadrando o interesse nacional à primeira categoria.

A concepção estadocêntrica do pensamento Realista das RI aponta, portanto, para a sobrevivência do Estado como pedra basilar do interesse nacional. Essa perspectiva realça a anarquia como causa permissiva de conflitos, permitindo dois comportamentos possíveis neste ambiente: a competição, redimensionando a balança de poder, e a emulação das práticas de sucesso dos Estados (Waltz 1979). Adicionalmente, ao considerar a competição no cerne das abordagens Realista e Neorrealista das RI, Aron desenvolve os Estados como organismos vivos em uma situação de luta pela sobrevivência e manutenção de soberania (Aron 1986, 128).

Mediante a caracterização do comportamento estatal como auto interessado e submerso em um ambiente anárquico, premissas do Realismo, é 
que se alinha a contribuição de Stephen Krasner. No mesmo fio condutor do Realismo político, Stephen Krasner (1978), com base na perspectiva de Morgenthau (2003), faz diferenciação entre o "dever oficial" e o "desejo pessoal” (Krasner 1978, 9). Desse modo, Krasner (1978) aponta que as decisões e ações do Estado devem estar relacionadas com os objetivos gerais do país, e não com preferências de pequenos grupos ou classes sociais, assim configurando o interesse nacional. Por conseguinte, abre-se espaço para uma análise de escopo racionalista, ou seja, centralizada em interesses estatais e no comportamento do Estado a fim de buscar padrões de regularidade estatal dentro do sistema internacional (Keohane 1984, 165).

Por seu turno, Hedley Bull (2002), representante da Escola Inglesa das RI, também fornece ferramenta conceitual-analítica para a construção do interesse nacional. Segundo o autor, a escassez de recursos naturais ou econômicos faz com que os Estados não abram mão de arranjos de poder em assuntos nos quais o mote é a preservação de seus interesses em seu significado mais largo, o interesse nacional. Dessa maneira, Bull (2002) afirma que o Estado elege quais são os pontos pertinentes a serem integrados em projetos formados por itens de segurança, bem-estar, estabilidade política ou econômica.

Diante do exposto, partindo da ideia de interesse nacional por Morgenthau até lograr uma perspectiva Realista embasada na obra de Stephen Krasner, perpassando por Hedley Bull para qualificar o interesse nacional, tem-se um conjunto da abordagem positivista dentro das teorias de RI. Todavia, tendo em vista a construção de um diálogo epistemológico neste trabalho, busca-se articular o interesse nacional também sob a ótica Construtivista, à luz da interação entre as concepções positivistas e pós-positivistas das RI.

Alexander Wendt (1999), na obra Social Theory of International Politics, busca redimensionar o debate ontológico entre o agente e a estrutura dentro das RI. Adotando premissas do Neorrealismo, como a estrutura sistêmica e distribuição das capacidades, Wendt enfatiza o papel das ideias e da distribuição de interesses no sistema internacional. Nessa caracterização das ideias, identidades e interesses, o autor contribui com o arranjo conceitual do interesse nacional.

Na literatura de Wendt (1999), o interesse nacional configura-se pelo compartilhamento de propriedades essenciais em virtude da sua identidade como corporação, gerando assim um interesse nacional universal. Essa identidade está assentada na ideia do self e do other, ou seja, como o Estado se percebe e se diferencia dos outros. Partindo da concepção de desejo (o que o Estado quer) e crença (o que o Estado é), os interesses e identidades dão força à atuação internacional dos Estados: sem identidade, os interes- 
ses não têm direção; sem interesse, as identidades não têm força motivacional (Wendt 1999).

Wendt (1999) aborda quatro interesses nacionais, que estão no cerne da caracterização do agente estatal, a saber: sobrevivência física, autonomia, bem-estar econômico e autoestima coletiva. Enquanto o Neorrealismo, sobretudo em Waltz (1979), assume a sobrevivência física do Estado como único interesse nacional, o pensamento Construtivista enquadra a dinâmica da sobrevivência física como um dos prismas do interesse nacional. Esse elemento diz respeito a assegurar a unidade territorial e a preservação do Estado como ente soberano no concerto anárquico internacional.

No que tange ao componente geopolítico, as concepções da teoria ideacional de Wendt têm relação com a concepção de interesse nacional da literatura geopolítica brasileira, sobretudo nas obras de Golbery do Couto e Silva (1980). A construção do interesse nacional, infere o geopolitólogo brasileiro, resulta de um “[ $[\ldots]$ processo histórico através do qual o grupo adquire e plasma uma consciência nacional” (Couto e Silva 1980, 252) e encontra terreno fértil na perspectiva Construtivista nas RI. Essa correlação pode ainda ser vista quando a Geopolítica Nacional dota de dinamismo o complexo hierarquizado de ideias e valores, interesses e aspirações específicas da comunidade em um dado momento histórico (Couto e Silva 1980, 169).

Portanto, considerando que as crenças intersubjetivas e o desejo do Estado de garantir a sua sobrevivência, o interesse nacional ganha forma neste debate epistemológico ao levar em conta a concepção sistêmico-estrutural com a alternativa Construtivista que, segundo Nogueira e Messari (2005), busca pavimentar uma ponte entre o positivismo e o pós-positivismo nas RI. Essa ponte busca dotar de caráter progressivo os estudos de TRI, visando a adicionar elementos explicativos e expandir a capacidade analítica das questões energéticas dentro dessa agenda. Esse esforço é uma das premissas destacadas pelo ecletismo analítico: estabelecer múltiplas conexões entre diferentes paradigmas e mecanismos sem simplificá-los (Sil e Katzenstein 2010, 2; Lake 2013, 577).

Sinteticamente, é a partir da configuração do interesse nacional para o pensamento teórico das RI que se articula a perspectiva geopolítica. Essa articulação se desenvolve uma vez que o Estado somente terá vantagens do ambiente geográfico a partir da definição dos seus objetivos e interesse nacionais, destacado por Meira Mattos (2011), ao elaborar que a geopolítica é a consciência geográfica do Estado.

No intuito de delinear a preocupação com a posição geoestratégica brasileira, Golbery do Couto e Silva (1980) oferece uma ferramenta epistemológica que concatena a perspectiva do interesse nacional dentro das RI com o panorama da geopolítica brasileira. Couto e Silva (1980) apresenta 
o conceito de Objetivos Nacionais Permanentes (ONP). Nesse conceito, somam-se os interesses e aspirações do grupo nacional tendo em vista sua sobrevivência como grupo e assegurando três condições básicas: autodeterminação, integração crescente e prosperidade (Couto e Silva 1980, 252).

Além dos ONP, o mesmo autor (1980) trabalha com Objetivos Nacionais Atuais (ONA), que representam "a cristalização [das aspirações e interesses nacionais], à luz das limitações impostas pelas possibilidades e circunstâncias do momento [...]” (p. 155). Esses ONA "são de natureza nitidamente estratégica que resultam da reação da Conjuntura, sobre os próprios ONP” (p. 255). Destarte, os ONA são a consolidação dos interesses nacionais em um dado momento e estão em função dos ONP, sendo estes objetivos políticos e os ONA de caráter estratégico, conclui Couto e Silva (1980). Entende-se, portanto, os ONA como desdobramentos dos ONP e alimentados por uma perspectiva conjuntural-estratégica. Diante disso, ao setor energético, por exemplo, ficou premente sua posição aos ONA, sobretudo após as crises do petróleo dos anos 1970, quando estratégias de fornecimento seguro e previsível de energia foram adotadas, como o lançamento do Proálcool (1979).

Os ONP, articulados por Golbery, convergem de forma particular com a ideia de interesse nacional da perspectiva Realista das RI, uma vez que evocam a sobrevivência, soberania e bem-estar, todos presentes nas obras de Morgenthau (2003), Aron (1986) e Waltz (1979). Adicionalmente, os mesmos ONP sugerem uma análise de construção do interesse nacional - pincelados pelo próprio Couto e Silva (1980) - tangenciando ao papel das ideias, das identidades (como o nacionalismo, por exemplo) e dos próprios interesses dos Estados, elementos presentes na análise Construtivista das RI.

Uma vez estabelecido o interesse nacional - ou os ONP, em termos geopolíticos - delineia-se a Estratégia. Carl von Clausewitz (1979) expõe que a Estratégia é um arcabouço teórico e moral que motiva o Estado a edificar o seu projeto de consecução de poder na escala mundial. Anatol Rapoport $(1979,20)$ apresenta que a Estratégia é a "capacidade de tirar proveitos dos conhecimentos humanos, culturais e materiais de um determinado Estado". Para Raymond Aron (1986, 72), "tanto a estratégia quanto a diplomacia estarão subordinadas à política, isto é, à concepção que a coletividade, ou aqueles que assumirem responsabilidades pela vida coletiva, fazem do interesse nacional”.

Por sua vez, Hage (2006) trabalha a Estratégia como uma ferramenta do planejamento de Poder Nacional, considerando este poder como a capacidade de fazer valer a vontade da unidade política mais bem preparada vis-à-vis seus pares que disputam os mesmos objetivos e desejam as mesmas vantagens escassas. Além disso, o mesmo autor afirma que a Estratégia 
não se limita apenas ao teatro da guerra (Hage 2006), ou seja, ela está presente tanto em tempos de guerra como de paz a fim de assegurar a estabilidade nacional. Em vista dos condicionantes políticos, Hage (2008, 171) desdobra o conceito de Estratégia como o planejamento do poder político do Estado ao levantar suas condições políticas e econômicas, domésticas e internacionais, a fim de montar cenários nos quais o país execute seu interesse nacional sem sofrer percalços ou desgastes. Daí os diferentes caminhos e cálculos - estratégias - feitos pelos tomadores de decisão em diversos momentos, à luz de condições favoráveis (por exemplo, autossuficiência energética) ou críticas (por exemplo, dependência energética).

$\mathrm{Na}$ busca de caracterizar a Estratégia, Couto e Silva $(1980,153)$ propõe o Poder Nacional como instrumento de ação da Estratégia, já que ele concatena a Estratégia Nacional como a "orientação e direção, tanto do desenvolvimento e reforço dos recursos nacionais, como de sua aplicação, a fim de promover efetivamente a consecução e salvaguarda dos Objetivos Nacionais (Atuais), a despeito dos antagonismos internos e externos existentes ou presumíveis" (Couto e Silva 1980, 155). Portanto, a Estratégia é a arte de aplicar e fortalecer o Poder Nacional diante dos antagonismos internos e externos que afrontam o interesse nacional, garantindo a segurança indispensável para a consecução deste interesse.

Ao fazer uma ponte epistemológica entre a narrativa da Geopolítica e a do Realismo Clássico das RI, Hage (2006, 34) menciona que “[...] a estratégia, o planejamento estratégico, [é] algo inerente às manifestações do poder nacional". Diante disso, os Estados nacionais guardam interesses geopolíticos, independentemente da configuração do sistema internacional ou do período histórico de que os atores fazem parte. Em adição, o mesmo autor escreve que "o planejamento estratégico, a geopolítica e a segurança são os fatores essenciais para compreender a situação do país em um nível em que a energia se qualifica como elemento relevante à consecução do poder do Estado" (Hage 2006, 24), dando substância à ideia de ONA, de Couto e Silva (1980).

No que respeita à energia e à definição de um planejamento estratégico em obediência aos objetivos nacionais, os Estados nacionais são centrais na adoção de políticas energéticas. Isso se deve porque a garantia de suprimento energético é responsabilidade essencial de qualquer Estado, sendo peça fundamental à sobrevivência deste (Fuser 2013, 45). Essa importância decisiva diz respeito à soberania dos Estados em impor políticas energéticas a fim de cumprir com suas responsabilidades nesse setor. Em diversos casos (por exemplo, Bolívia e Brasil), os instrumentos estatais para arcar com as responsabilidades energéticas são as próprias empresas estatais de hidrocarbonetos. 
A partir das ideias de Estratégia e Objetivos Nacionais (Couto e Silva 1980), busca-se articular um vértice analítico importante: a Geoestratégia. Ao considerar o planejamento geopolítico como um planejamento de segurança de um país em termos de seus fatores geográficos, Couto e Silva (1980, 166) conjuga essa perspectiva ao inferir uma ideia preliminar da Geoestratégia como a "fundamentação geográfica de uma diretriz estratégica”. Assim, as decisões políticas vão ditar a cadência e a operacionalização tanto da Estratégia quanto da Geopolítica nacionais: "a esta [Geopolítica] como colaboradora de suas próprias formulações, àquela [Estratégia] como subordinada sua, com missões definidas a cumprir num âmbito operacional mais reduzido" (Couto e Silva 1980, 102).

No campo da Geoestratégia, os fatores geográficos condicionam, em maior ou menor grau, todos os elementos e fundamentos do Poder Nacional, sejam eles políticos, econômicos, psicossociais ou militares e, portanto, "proporcionam uma fundamentação e a proposição de diretrizes a qualquer das componentes admitidas da Estratégia Geral” (Couto e Silva 1980, 167). Ademais, em que pese a íntima correlação entre Poder Nacional e Geopolítica, Bonanate (1997, 432) indica que "o Poder Nacional e a geopolítica são termos pares e inseparáveis para melhor posição da unidade política no sistema internacional”.

A adequação do Poder Nacional aos interesses nacionais é conjugada também na forma de uma Política de Consecução, isto é, a maneira pela qual se contemplarão os Objetivos Nacionais diante do seu respectivo condicionamento espaço-temporal. É a Política de Consecução a manobra a conduzir no campo da Estratégia Nacional. Assim, será através da Política de Consecução que serão estabelecidas, como orientação geral, as bases do comportamento governamental visando à consecução dos Objetivos predeterminados (Couto e Silva 1980, 257). No campo energético, a Política de Consecução será revelada em termos de Estratégia de Segurança Energética traduzida em uma política energética nacional de diversificação, qual seja a redução da dependência de um país em uma única fonte de suprimento energético.

No prisma energético, a Geopolítica tem uma dinâmica própria revelada pela Geopolítica Energética. Esse campo começa a ser discutido a partir do crescimento exponencial das necessidades de energia importada dos grandes países industrializados (Conant e Gold 1981). Diante disso, Oliveira (2012, 77) argumenta e conceitua a Geopolítica Energética com base em um conjunto de elementos geopolíticos e estratégicos para a exploração (infraestrutura, transporte, uso final) combinado com a distribuição geográfica das principais reservas de recursos energéticos, focalizando nos países importadores e exportadores. Conant e Gold (1981), destacam 
que os fatores de localização geográfica devem ser observados toda vez que forem analisadas as questões de acesso às matérias-primas ou recursos energéticos primários como o petróleo e gás natural, ou seja, o "efeito que a localização dos recursos possui na política dos Estados” (Skeet 1996, 265).

Nessa abordagem da Geopolítica Energética observada como passível de ser objeto para um conflito, é necessário fazer um paralelo ao pensamento Realista das RI. Morgenthau (2003), por exemplo, não enxerga a política internacional, em todo o século XX, separada do petróleo e da dependência que os Estados industrializados passaram a ter em relação a essa matéria-prima. Além de Morgenthau (2003), Michael Klare (2001), nas obras de Segurança Energética, também desenha um mundo desconcertado energeticamente ao traduzir a nova geografia do conflito, de escopo eminentemente energético.

A Geopolítica Energética, como supramencionado, não implica ausência de conflitos, uma vez que opera no palco anárquico do sistema internacional, portanto "a localização geográfica, a dimensão territorial da unidade política, a grande escala demográfica, a infraestrutura e recursos naturais são categorias clássicas da política internacional, e da geopolítica, que ainda têm o poder de impulsionar conflitos entre as unidades políticas” (Hage 2006, 50). Sem embargo, a análise da Geopolítica Energética possui uma natureza ontológica essencialmente calcada na ideia do Estado unitário, isto é, uma abordagem estadocêntrica, a qual deve ser superada, na visão de Graaf et al. (2016,6), a fim de incorporar o papel de relevância das companhias petrolíferas, corporações, consumidores, cidadãos, cooperativas energéticas e mercados.

Em síntese, na busca do bem-estar, sobrevivência e soberania - ou seja, na busca dos ONP - em meio a um cenário energético incerto, sobretudo após os anos 1970, é que o componente geográfico dos recursos energéticos desperta atenção na elaboração de uma estratégia energética. Antes disso, é necessário compreender as arestas conceituais de uma Estratégia de Segurança Energética dentro da agenda de Estudos de Segurança Internacional, traduzindo esse diálogo epistemológico para a atual conjuntura.

\section{SEGURANÇA ENERGÉTICA: A BUSCA DE UMA ESTRATÉGIA PRÓPRIA}

Com o término da Guerra Fria, novos atores e novas ameaças foram incorporadas aos estudos de segurança internacional, dentre elas a questão da energia (Baldwin 2007, 99). Nessa perspectiva, a Escola de Copenhagen - com uma concepção discursiva - traz à tona uma alternativa às concepções objetivas (ausência/presença de ameaças concretas) e subjetivas 
(sentimento de estar sendo ameaçado) dos estudos de segurança internacional. Assim, essa escola oferece uma ampliação das ameaças e objetos de referência, com maior atenção ao nível regional com foco na securitização, ${ }^{1}$ a fim de adicionar elementos do Construtivismo às premissas dos Estudos Estratégicos tradicionais (Buzan e Hansen 2009, 36).

Pari passu à evolução dos temas de Segurança Internacional no pós-Guerra Fria e consequente inserção da temática da Segurança Energética, Klare (2006) verifica, por exemplo, que as questões de recursos reassumiram um papel central no planejamento militar dos EUA (Klare 2006, 9). Apesar dessa centralidade no planejamento nacional como um Objetivo Nacional Permanente - o de suprimento energético constante e seguro para mover a engrenagem econômica nacional -, as questões concernentes aos energéticos vêm demandando atenção na formulação de estratégias efetivas para garantia desse suprimento. Sem embargo, as concepções tradicionais de segurança energética - preços razoáveis e um suprimento seguro (Klare 2006) - devem ser permeáveis, a fim de incorporar elementos das políticas fiscal, social, externa, tecnológica e climática (Graaf et al. 2016, 18).

Essa Estratégia Energética, derivada de uma operacionalização dos ONP para o campo energético, é vital não só para a segurança nacional, mas para o desenvolvimento econômico. Isso porque a importância da questão energética na contemporaneidade fica evidente ao se apontar para o caráter fundamental do componente energético para a vida moderna: "Sem petróleo, praticamente não existe mobilidade, e sem eletricidade - e energia para gerá-la - não haveria a era da Internet” (Yergin 2011, 522).

A despeito das crises do petróleo dos anos 1970, a energia volta no topo das preocupações estratégicas globais a partir dos anos 2000, isso porque é observável a dissonância entre o crescimento acelerado do consumo energético global e o ritmo lento da expansão da oferta dos energéticos, sobretudo o petróleo. Em números, as reservas provadas de petróleo no mundo mantém-se no mesmo patamar desde 2016 (1,7 trilhão de barris), enquanto a demanda apresenta crescimento. A produção mundial, em 2017, foi a de 92,6 milhões de barris/dia, enquanto que o consumo mundial de petróleo totalizou 98,2 milhões de barris/dia, aumento de 1,8\% em relação a 2016 (ANP 2018). Além disso, uma série de desafios às questões energéticas emergiram na América Latina no alvorecer dos anos 2000: ressurgimento do nacionalismo energético e o fortalecimento das empresas estatais de energia na América do Sul (YPFB na Bolívia, por exemplo).

Além disso, Klare (2001) atribui essa crescente importância dos recursos à adoção de uma política de segurança econocêntrica, ou seja, de prevalência dos ONP. Essa postura quase sempre leva a uma ênfase crescente 
de proteção de recursos, sobretudo por aqueles Estados que dependem da importação de matérias-primas para o seu desempenho industrial. Klare (2006) aponta três dínamos do debate atual sobre energia: o crescente consumo dos países em vias de desenvolvimento, geopolítica centrada na energia (sobretudo na Eurásia) e o pessimismo acerca do futuro da energia, sobretudo pela lenta inserção das energias renováveis em países de alta produção e dependência de combustíveis fósseis em países como o Brasil que, a despeito de possuir uma matriz energética de alta incidência de renováveis, vem aumentando gradualmente a participação de combustíveis fósseis (por exemplo, o petróleo) na sua matriz energética.

Em que pese a dimensão epistemológica da segurança energética, Yergin (2011) trabalha com a abordagem multidimensional desse conceito, escalonando quatro dimensões. Primeiro, a dimensão da segurança física, que abarca a proteção dos ativos, da infraestrutura, das redes de abastecimento e das rotas comerciais, criando provisões para substituições rápidas, quando necessário. Segundo, o acesso físico, contratual e comercial à energia, enfatizando a capacidade de produzir e adquirir. Terceiro, a segurança energética como sistema composto por políticas nacionais e instituições internacionais destinadas a responder, de maneira coordenada, a interrupções e deslocamentos do abastecimento energético. Quarto, os investimentos: a segurança energética exige políticas e um clima comercial que promovam o investimento e o desenvolvimento de modo a garantir a existência de suprimentos e infraestrutura adequados em qualquer momento no futuro.

Assim, articula-se que buscar segurança energética não implica apenas combater a enorme variedade de ameaças existentes ao fluxo contínuo a preços razoáveis de energéticos, mas dialoga intimamente com as relações entre os países, correlações, justaposições e impacto da energia na segurança nacional como um todo (Yergin 2011, 523). Por isso, faz-se mister compreender um eixo basilar da segurança energética que é o sustentáculo de uma estratégia: a dependência.

A dependência energética como variável da estratégia de segurança energética apresenta duas resultantes. Primeiro, a soberania energética. Essa perspectiva de soberania energética varia entre países exportadores e países importadores, configurando-se como um conceito político. Na perspectiva dos países desenvolvidos importadores (Estados Unidos e Japão, por exemplo), o aporte confiável, amplo e diversificado e a preços acessíveis de suprimentos de petróleo e gás é crucial. Já os países detentores de excedentes exportáveis de energia - quase todas as sociedades que superaram sua condição colonial ou neocolonial ao longo do século XX - mostram-se inclinados a formular suas políticas com base em soberania ener- 
gética, com a intenção de atingir objetivos de desenvolvimento econômico e social, definidos a partir do Estado (por exemplo, Paraguai e Bolívia) (Fuser 2013, 146; Tasca 2017).

A segunda resultante é o preço. Deve-se levar em conta, no cálculo estratégico-energético, o preço do energético importado. Esse preço não deve sofrer alterações que possam comprometer o fornecimento e o equilíbrio econômico do consumidor. Nesse item, a principal reivindicação das parcerias energéticas refere-se ao item anterior, a soberania energética, ou seja, à capacidade de um Estado de exercer controle e autoridade para exercer de maneira racional e sustentável a exploração de seus recursos energéticos, sem perder de vista a manutenção de uma liberdade para minimizar custos associados às pressões externas (Lahoud 2005, 7). Para esse elemento, as relações energéticas entre Brasil e Paraguai, no concernente a Itaipu e à soberania energética paraguaia, observa-se a tentativa de renegociação do preço da energia excedente do Paraguai exportada ao Brasil e da inclusão da revisão de preços para a renovação do acordo em 2023, quando a usina terá seus custos amortizados.

Ao considerar a dependência energética como um fator chave na busca e manutenção da segurança energética e, por conseguinte, dos Objetivos Nacionais Permanentes, a Estratégia de Segurança Energética (ESE) configura-se como a operacionalização dos ONP para a questão da energia. A ESE pode ser definida como “o conjunto de ações políticas, envolvendo desde o planejamento, os processos de tomada de decisão, a implementação das políticas específicas planejadas, até a avaliação dos resultados obtidos na busca pela ampliação da Segurança Energética de um Estado” (Oliveira 2012, 82).

Diante dessa definição, cada Estado pode adotar uma Estratégia Energética diferente, desde que atenda aos seus objetivos nacionais. De maneira simplificada, a literatura classifica esse tipo de Estratégia em três grandes categorias, cuja diferenciação se dá pela forma como são operacionalizadas. A primeira Estratégia é a Estratégia da Integração Energética Regional, a qual abarca a integração da infraestrutura e de cadeias produtivas de energia em uma dada região ou continente. Geralmente, essa estratégia vem permeada de iniciativas de integração regional (Oliveira 2012). A Unasul, por exemplo, tem como um de seus pilares a questão energética, buscando espaço para a cooperação e integração energética regional através da Iniciativa para Integração da Infraestrutura Regional Sul-Americana (IIRSA), o que dá forma a essa Estratégia de Integração Regional Energética. Entretanto, além da dificuldade de se lograr consenso entre os mecanismos da integração energética regional (construção de dutos, tarifas comuns, por exemplo), essa estratégia apresenta dificuldades para alguns energéticos como o gás natural, uma vez que integrar um ga- 
soduto por grandes distâncias pode aumentar seus custos de distribuição, além de ampliar trajetos passíveis de interrupção no fornecimento.

A segunda alternativa estratégica é a Estratégia da Autossuficiência Energética. Embora essa opção de busca por autonomia energética possa minimizar o problema dos países que são muito dependentes de energia importada, considera-se que ela seja virtualmente inviável de ser a principal estratégia de segurança energética para grandes potências (Klare 2008). Essa estratégia pode ser operacionalizada mediante: diversificação da matriz energética, descentralização da infraestrutura de geração e distribuição de energia, inovação energética (por exemplo, inovação energética tecnológica e novos combustíveis) e a eficiência energética (ganhos de eficiência estruturais).

Segundo Klare (2006), a estratégia da autossuficiência se refere ao fato de ter margem de manobra em termos de liberdade de ação, além de integridade, no que tange ao cumprimento dos valores nacionais ao tomar decisões de política energética, tendo em conta ainda os interesses no longo prazo. Para levar a cabo essa estratégia, explica Klare (2006), é necessário: 1) estabelecer a separação entre as aquisições de energia e os compromissos de segurança com o estrangeiro; 2) diminuir a dependência com relação ao energético importado (praticando a autolimitação e eficiência energéticas) e 3) preparar o caminho para a inevitável transição a uma economia, sobretudo, pós-petróleo.

Para ilustrar o papel dessa estratégia, a política energética brasileira para combustíveis líquidos de meados dos anos 1970 primou pela diminuição da dependência do petróleo importado através do lançamento do Proálcool. Esse programa buscou garantir a segurança energética brasileira durante uma década de crises do petróleo (1973 e 1979). Essas crises, por sua vez, levaram a desequilíbrios na balança de pagamentos brasileira, altamente dependente de petróleo importado. Adiciona-se ainda que, nesse período, fatores internacionais e domésticos impulsionaram a política brasileira de etanol: capacidade ociosa das usinas domésticas, queda do preço internacional do açúcar, aumento do preço do petróleo e a necessidade de evitar a corrosão de divisas internacionais com a importação de petróleo e derivados. Portanto, condicionantes internacionais (preço quadruplicado do petróleo importado) e vetores domésticos (capacidade de produção de um energético nacional) foram motores dessa estratégia orientada para a autossuficiência.

Sem embargo, há dois problemas em se falar em autossuficiência energética em matrizes energéticas dominadas por combustíveis fósseis. Primeiro, eles são finitos e distribuídos de forma desigual na geografia mundial, acirrando as tensões geopolíticas por conta desses recursos. 
Segundo, a operacionalização dessa estratégia deve vir acompanhada de energias renováveis, as quais demandam investimentos de longo prazo e que enfrentam dificuldade de penetração nas matrizes energéticas dos países. Essa dificuldade decorre de uma alta dependência de combustíveis fósseis, fenômeno também chamado de carbon lock-in (Unruh 2000), consubstanciado pela $15^{\mathrm{a}}$ posição do Brasil no ranking mundial de reservas provadas de petróleo (12,8 bilhões de barris) (ANP 2018).

Por fim, a terceira estratégia abordada neste trabalho é a Estratégia do Aumento da Segurança do Fornecimento Externo de Energia. Essa alternativa tem duas formas de operacionalização: 1) através da diversificação dos fornecedores externos e 2 ) por meio da militarização do controle de recursos energéticos no exterior. Esta última forma implica a tentativa de controlar diretamente as fontes de recursos energéticos no exterior, muitas vezes através da securitização e militarização da segurança energética, diversas vezes envolvendo disputas entre países importadores e exportadores de energia, com a ocorrência de guerras pelo controle de jazidas petrolíferas (ex.: Guerra do Golfo) (Oliveira 2012; Hage 2008, 170).

Desse modo, a primeira forma de operacionalização desta última estratégia é obtida através de acordos comerciais, mediante influência político-diplomática ou até mesmo por simples mecanismos de mercado. Outrossim, a alternativa de diversificação dos fornecedores externos de energia é apontada pela narrativa de Daniel Yergin $(2006,8)$ verificando que "a diversificação permanecerá como o princípio fundamental da segurança energética tanto para o petróleo quanto para o gás”. Além disso, a história mostra que a diversificação de parcerias e de fontes energéticas datam da Primeira Guerra Mundial, a partir da decisão de Churchill de importar petróleo para substituir o carvão como o energético que movia a marinha britânica (Pimentel 2011; Klare 2001; Yergin 2006).

$\mathrm{Na}$ tentativa de reduzir a dependência brasileira do gás natural importado da Bolívia, por exemplo, estratégias de diversificação foram implementadas. A principal delas é a crescente importação de gás natural liquefeito (GNL). Ao passo que as importações brasileiras de gás natural, entre 2008 e 2017, caíram 22\%, a importação de GNL aumentou de 35 milhões de $\mathrm{m}^{3} \mathrm{em} 2008$ para 1.756 milhões de $\mathrm{m}^{3} \mathrm{em} 2017$, um aumento de $98 \%$. Não só a quantidade de GNL importada aumentou, mas também a quantidade de países dos quais importa. Em 2008, Trinidad e Tobago era o único país exportador de GNL ao Brasil. Em 2015, $13^{2}$ eram os países exportadores de GNL, reduzindo para 5 (Angola, Catar, EUA, Nigéria e Trinidad e Tobago), em 2017.

Além da diversificação de parceiros, a estratégia de importação de GNL de países africanos, por exemplo, tem duas arestas geopolíticas (Mattos 
2011) ao tangenciar a importância geoestratégica do Atlântico Sul, no qual $7.408 \mathrm{~km}$ da costa marítima brasileira está debruçada. Primeiro, como ponte estratégica Natal-Dacar e, segundo, como corredor para a importação de energéticos - notadamente o GNL, que é regaseificado nos portos brasileiros.

Desse modo, a diversificação de parceiros, bem como a de fontes energéticas, é um dos grandes norteadores da política energética. Isso ocorre tanto em termos de diversificar a matriz energética com recursos renováveis para reduzir a dependência de produção - ainda que a dependência tecnológica seja mantida - quanto para adequar a estratégia energética para um mundo pós-petróleo, qual seja aquele que utilize o gás natural como combustível de transição ou que aposte crescentemente na energia solar.

\section{CONSIDERAÇÕES FINAIS}

Motivada pela compreensão e conexão entre TRI, Geopolítica e Estudos de Segurança Internacional, essa narrativa buscou avançar no debate epistemológico acerca da Geopolítica Energética. Por conseguinte, a primeira parte deste trabalho trouxe um diálogo epistemológico sobre o interesse nacional a partir da literatura das RI, visando a conjugar esse conceito com a perspectiva da Geopolítica brasileira. Partindo-se da visão do Realismo político das RI e da concepção Construtivista dessa área, aliada à literatura geopolítica brasileira, percebe-se essas duas perspectivas - das teorias de RI e da Geopolítica - como complementares, no que tange à epistemologia do interesse nacional. Essa ponte interdisciplinar, cujo amálgama é a epistemologia, apresentou-se como fundamental para compreender a concepção da Geopolítica Energética partindo-se da narrativa teórica das RI.

A relação de complementaridade entre a Geopolítica brasileira e a teoria das RI, em termos epistemológicos, é observada ao colocar em evidência as concepções de Estratégia e Geoestratégia, ambas fruto do interesse nacional. Por sua vez, o interesse nacional é central, tanto na abordagem das RI quanto na da Geopolítica, pois é a partir dele que os Estados buscarão a consecução do Poder Nacional através da Estratégia - e da sua vertente geográfica, a Geoestratégia.

Em seguida, na busca de ajustar os estudos de Segurança Energética à agenda dos Estudos de Segurança Internacional, observou-se a evolução da temática no pós-Guerra Fria pari passu à concepção discursiva de manifestação de novas ameaças. Essa concepção é trabalhada pela Escola de Copenhagen, dentro dos ESI, e observa o tema da energia como latente e pertencente ao novo rol das ameaças do mundo pós-bipolaridade. Nessa mesma esteira de observação da energia como elemento pivô de debates 
contemporâneos, Daniel Yergin, Michael Klare, Lucas Oliveira e Igor Fuser observam, cada um da sua forma e com seu instrumental analítico, a crescente importância das questões energéticas para as RI.

$\mathrm{Na}$ análise da segurança energética nacional, Conant e Gold (1981) oferecem ferramenta importante para o diálogo conceitual da dependência energética. Esse instrumental, por sua vez, enriquece a perspectiva de soberania e segurança energética, ambos conceitos políticos que são trabalhados por diferentes Estados, simultaneamente, em um tabuleiro internacional desigual. Simultaneamente às concepções da Segurança Energética e da Estratégia, molda-se uma tipologia referente a Estratégias de Segurança Energética. Nas linhas acima, foram abordadas três estratégias: 1) a Estratégia de Integração Energética Regional; 2) a Estratégia de Autossuficiência Energética e 3) a Estratégia de Aumento de Segurança do Fornecimento Externo de Energia.

Destarte, a partir da terceira estratégia - Estratégia de Aumento de Segurança do Fornecimento Externo de Energia - é que se articula a diversificação dos parceiros energéticos como peça estratégica fundamental à garantia da segurança energética nacional diante dos condicionantes do interesse nacional e da geopolítica energética nos quais os países estão submersos dentro do xadrez internacional. Contudo, o texto também apontou para algumas limitações de ordem técnico-política das estratégias energéticas.

Ademais, essa narrativa buscou avançar na evolução epistemológica de Geopolítica Energética. Ressalta-se que que os estudos sobre política energética e energia per se vêm incorporando desafios da transdisciplinaridade por integrar as ciências humanas (por exemplo, Ciência Política, Sociologia e Relações Internacionais) com a natureza técnica dos assuntos energéticos. Contudo, desafios a essa articulação permanecem, como as limitações que as estratégias energéticas calcadas em hidrocarbonetos oferecem - seu horizonte de médio prazo -, que podem ser minimizados, por exemplo, pelo desenho de uma Geopolítica das Energias Renováveis (Scholten e Bosman 2016). Assim, é possível pensar em uma ampliação dessa agenda com a incorporação de vetores próprios de energias renováveis, suas externalidades e seu diferencial competitivo - convergência econômica (Giddens 2009) - para os Estados que a implementarem como Objetivos Nacionais Permanentes vis-à-vis o mote do desenvolvimento sustentável.

\section{REFERÊNCIAS}

ANP. Agência Nacional do Petróleo, Gás Natural e Biocombustíveis. 2018. Anuário Estatístico Brasileiro do Petróleo, Gás Natural e Biocombustíveis 2018. Disponível em:<https://goo.gl/7De1J3>. Acesso em: 21 ago. 2018. 
Aron, Raymond. 1986. Paz e Guerra Entre as Nações. Coleção Pensamento Político 7. 2. ed. Brasília: Universidade de Brasília.

Baldwin, David. 2007. Security Studies and the End of the Cold War. In: Buzan, Barry; Hansen, Lene. International Security. 3: 99-120. Londres: SAGE Publications.

Blackwill, Robert e Meghan O'Sullivan. 2014. America's Energy Edge: The Geopolitical Consequences of the Shale Revolution. Foreign Affairs, March/April.

Bonanate, Luigi. 1997. Estratégia e Política dos Armamentos". In BOBBIO, Norberto et al. (org). Dicionário de Política. 1. 10. ed. Brasília: Universidade de Brasília.

British Petroleum. 2017. The effect on LNG growth on global gas markets. Disponível em: <https://goo.gl/vLRN7E>. Acesso em 09 mai. 2018.

Buzan, Barry e Lene Hansen. 2009. The Evolution of International Security Studies. Cambridge: Cambridge University Press.

Bull, Hedley. 2002. A Sociedade Anárquica. Brasília: Ed. Da UnB/IPRI.

Buzan, Barry, Ole Waever e Jaap de Wilde. 1998. Security: A New Framework for Analysis. Boulder: Lynne Rienner, Londres.

Clausewitz, Carl von. 1979. Da Guerra. Prefácio de Anatol Rapoport. São Paulo: Martins Fontes.

Conant, Melvin A. e Fern Gold. 1981. A geopolítica energética. BIBLIEX.

Couto e Silva, Golbery do. 1980. Conjuntura política nacional: o Poder Executivo \& geopolítica do Brasil. 2. ed. Rio de Janeiro: J. Olympio. XIV, 273 p.

Fierke, K. 2007. Critical Approaches to International Security. Cambridge, Reino Unido: Polity.

Fuser, Igor. 2008. Petróleo e poder: envolvimento militar dos Estados Unidos no Golfo Pérsico. São Paulo: Editora UNESP: Programa San Tiago Dantas de PósGraduação em Relações da UNESP, Unicamp e PUC-SP.

Fuser, Igor. 2013. Energia e Relações Internacionais. São Paulo: Saraiva.

Giddens, Anthony. 2009. The Politics of Climate Change. Polity Press: UK, 272p.

Graaf, Thijs, Benjamin Sovacool, Arunabha Ghos, Florian Kern e Michael Klare. 2016. States, Markets, and Institutions: Integrating International Political 
Economy and Global Energy Politics. In.: Graaf, Thijs; Sovacool, Benjamin; Gosh, Arunabha; Kern, Florian and Klare, Michael (Eds.). The Palgrave Handbook of the International Political Economy of Energy. Palgrave Macmillan, 755p.

Hage, José Alexandre Altahyde. 2006. Bolívia, Brasil e a Guerra do Gás. Tese (Doutorado). Departamento de Ciência Política do Instituto de Filosofia e Ciências Humanas da Universidade Estadual de Campinas.

Hage, José Alexandre Altahyde. 2008. O poder político na energia e relações internacionais: o difícil equilíbrio entre o direito e a busca de segurança do Estado brasileiro. Revista Brasileira de Política Internacional. 51 (1): 169-186.

Keohane, Robert. 1984. After Hegemony: Cooperation and Discord in the World Political Economy. Princeton (NJ): Princeton University Press.

Klare, Michael T. 2001. Resource Wars: the new landscape of global conflict. New York: Owl Books.

Klare, Michael T. 2006. Sangre y Petróleo: Peligros y consecuencias de la dependencia del crudo. Barcelona: Ediciones Urano.

Klare, Michael T. 2008. Energy Security. In: Williams, Paul D. Security Studies: An Introduction. New York: Routledge.

Krasner, Stephen. 1978. Defending the National Interest: Raw Materials Investments and U.S. Foreign Policy. Princeton (NJ): Princeton University Press.

Lahoud, Gustavo. 2005. Una Aproximación Teórica a la Soberanía Energética e Integración Regional Sudamericana. Buenos Aires: Instituto de Investigación en Ciencias Sociales (IDICSO) de la Universidad del Salvador.

Lake, David. 2013. Theory is dead, long live theory: The end of the Great Debates and the rise of eclectism in International Relations. European Journal of International Relations, 19: 567-587.

Manning, Robert. 2014. The Shale Revolution and the new geopolitics of energy. Washington, DC: Atlantic Council.

Mattos, Meira. 2011. Geopolítica. 1. Rio de Janeiro: FGV Editora, 315p.

Morgenthau, Hans. 2003. Política entre as nações. Brasília: Editora Universidade de Brasília. Imprensa Oficial do Estado de São Paulo: Instituto de Pesquisa de Relações Internacionais. 
Nogueira, João Pontes e Nizar Messari. 2005. Teoria das Relações Internacionais: correntes e debates. Rio de Janeiro: Elsevier, 250 p.

Oliveira, Lucas Kerr de. 2012. Energia como Recurso de Poder na Política Internacional: Geopolítica, Estratégia e o Papel do Centro de Decisão Energética. 40of. Tese (Doutorado) - Porto Alegre: Universidade Federal do Rio Grande do Sul.

Pimentel, Fernando. 2011. O fim da era do petróleo e a mudança do paradigma energético mundial: Perspectivas e desafios para a atuação diplomática brasileira. Brasília: FUNAG.

RAPOPORT, Anatol. Prefácio. In: Clausewitz, Carl von. 1979. Da Guerra. São Paulo: Martins Fontes.

Scholten, Daniel e Rick Bosman. 2016. The geopolitics of renewables: exploring the political implications of renewable energy systems. Technological Forecasting E Social Change, 103: 273-283.

Sil, Rudra e Peter Katzenstein. 2010. Beyond Paradigms. Analytic Eclecticism in the Study of World Politics. New York: Palgrave Macmillan.

Skeet, Ian. 1996. Geopolitics of Energy. Energy Exploration Eீ Exploitation. 14 (3-4): 265-272.

Tasca, Tiago G. 2017. De Roboré aos Anos 2000: a Bolívia como Vértice de (In) Segurança Energética Brasileira? Conjuntura Internacional, 14 (1): 12-24.

Unruh, Gregory. 2000. Understanding carbon lock-in. Energy Policy. 28: 817-830.

Waltz, Kenneth. 1979. Theory of International Politics. New York: McGraw Hill.

Wendt, Alexander. 1999. Social Theory of International Politics. Cambridge: Cambridge University Press.

Yergin, Daniel. 2006. Ensuring Energy Security. Foreign Affairs. 85 (2). March/ April.

Yergin, Daniel. 2011. A Busca: energia, segurança e a reconstrução do mundo moderno. Tradução de Ana Beatriz Rodrigues. Rio de Janeiro: Editora Intrínseca. 


\section{NOTAS}

1. “[ ...] processo social pelo qual grupos constroem algo como ameaça [...]” (Buzan e Hansen 2009, 36). Além disso, Fierke (2007) verifica que "a securitização de determinado tema - como meio ambiente, narcotráfico, migrações e energia - ocorre quando um Estado decide encará-lo como uma questão que põe em jogo a sobrevivência e/ou outros interesses vitais do país. Quando um tema é "securitizado", os atores estatais passam a abordá-lo sob o prisma da segurança nacional, o que justifica a ameaça ou o uso da força militar para atingir os objetivos a ele relacionados" (Fierke 2007, 102-104).

2. Argélia, Bélgica, Catar, Emirados Árabes Unidos, Espanha, EUA, França, Guiné Equatorial, Holanda, Nigéria, Noruega, Portugal, Reino Unido e Trinidad e Tobago (ANP 2018). 


\section{RESUMO}

O objetivo deste artigo é apresentar um diálogo epistemológico partindo do conceito de interesse nacional e, por meio da geopolítica energética, compreender a estratégia de segurança energética orientada para a diversificação. Este trabalho é estruturado em: 1) aproximações teóricas entre o interesse nacional e a geopolítica energética; 2) estratégias de segurança energética.

Palavras-chave: Geopolítica energética; Teoria de Relações Internacionais; Estratégias energéticas.

\section{ABSTRACT}

The aim of this article is to present an epistemological dialogue starting with the idea of the national interest through energy geopolitics in order to comprehend an energy security strategy oriented to diversification. This article is divided in two sections: 1) theoretical remarks between national interest and energy geopolitics; 2) energy security strategies.

Keywords: Energy Geopolitics; International Relations Theory; Energy Strategies. 